\title{
The Effects of Instructions in L1 and L2 in EFL Listening Classes on A2 Level Learners
}

\begin{abstract}
The current study aimed to investigate the effects of providing instructions in L2 listening activities on the participants' performance in the classroom as well as the participants' views regarding the use of L1. The study included 48 students from the preparatory classes in the School of Foreign Languages, at a state university in Turkey. Through the post-test, only quasi-experimental research design, the participants' performance was compared in classes with L1 and L2 instructions in the listening activities. The results indicated that the participants in the experimental group scored higher than those in the control group who were exposed to L2 instructions.

Keywords: first language use, L1, giving instructions, listening, A2 level, EFL
\end{abstract}

\section{Introduction}

Learners' L1 was possibly considered as 'elephant in the room' of English Language teaching (Levine, 2011) and it was generally believed that L1 itself should be avoided by learners as indicated by several scholars. For example, Gabrielatos (2001) stated that "L1 use in ELT: [is] not a skeleton, but a bone of contention" (p. 33). Lee (2018) indicated that the debate on the L1 use could be related to the common belief that when the students are in the process of learning more than one language, there might be interference and linguistic codes might become disorganised totally, resulting in perpetual communication difficulties. Accordingly, the time allocated for L1 use might be considered as wasted time as it could have been used for exposing learners to input in L2. L1 use by teachers during the classroom activities, such as giving instructions and interaction in other skills, is not advised since it might prevent the students from benefiting from contextual cues or inferences that might aid comprehension (Oflaz, 2009).

It might be inevitable to use L1 in foreign language classes in some situations (Lightbown \& Spada, 2020). As several authors emphasised in their research (e.g.,

Tarkan Gündüz, School of Foreign Languages, Kınıklı Campus, 20070 Denizli, gunduztarkan@gmail.com, https://orcid.org/0000-0002-8893-4013

Ferit Kılıçkaya, Department of Foreign Language Education, Faculty of Education, A Block, Istiklal Campus, 15030 Burdur, Phone: 00902482134068, ferit.kilickaya@gmail.com, http://orcid.org/00000002-3534-0924 
Greggio \& Gil, 2007; Jingxia, 2008; Lewicka-Mroczek \& Wajda, 2017; Oflaz, 2009) instructors might utilise the L1 if it is necessary in various cases. Swan (2007) believed that L1 is a reflection of cultural identity and it might be considered as a point that needs to be underlined. Moreover, the contextualisation of listening activities with the assistance of L1 cultural items is highly important and therefore requires further exploration. Therefore, it could be important to study the effectiveness level of L2 instruction when it is integrated with L1. To further probe into the use of $\mathrm{L} 1$, the study aimed at examining and comparing the performances of A2 level adult learners in listening activities when the activity instructions are given in L1 and L2 separately in two homogeneous classes.

\section{Literature review}

The use of L1 has been in the process of attracting attention from teachers and researchers recently and its methodological value is widely discussed (Atkinson, 1987; Hall, 2018; Lee, 2018; Nation, 2003). For example, Nation (2003) put forward a balance between two distinct sides of the idea of using or not using the L1. It can also be proposed that if using the learners' L1 contributes to classroom learning and teaching practices, L1 should not be avoided (Zulfikar, 2018). Similarly, Nation (2003) asserted that L1 use should not be prohibited by stating that teachers should be respectful of the learners' $\mathrm{L} 1$ and need to avoid classroom practices that make the L1 seem unnecessary. What Nation (2003) stated regarding the use of L1 may not be deniable since when the teacher leads students to perceive that L2 is viewed better than their L1, they might prefer not to use their L1 and resist learning languages. However, the teacher cannot permit students to overuse L1 in the classroom as "it is the English teacher's job to help learners develop their proficiency in English" (Nation, 2003, p. 6). Another research study focusing on the amount of L1 and L2 used in English classes at lower secondary schools was conducted by Najvarová (2011). The aim of the study was, among other things, to identify the proportion between the target language and L1 used by both teachers and learners. Employing video recordings, the study revealed that, in an average lesson, L1 was used for $40 \%$ of the time. Again, significant differences were discovered between individual teachers. While one of them was observed to use the L2 for $68 \%$ of the lesson time, another teacher spent the same amount of time using L1. These findings might lead us to go into details about teachers' attitudes and students' success based on L1 use. As a response to this, Macaro's (2001) optimal position proposed that "some aspects of learning might be enhanced by the use of L1; therefore, there should be a constant exploration of pedagogical principles regarding whether and in what ways L1 use is justified" (p. 535).

Macaro's (2001) study in 14 French language lessons revealed that the use of L1 was found out to be low level among the teachers. On the other hand, it was observed that the communicative content of an expression in the L1 can be trans- 
ferred more swiftly than the equivalent content in L2 communication. Additionally, Nation (2003) suggested that a balanced approach was necessary because there appeared to be a significant role of L1, and the case of the increasing amount of L2 use in the teaching environment needs to be recognised. This can both prevent students' negative feelings and help them learn L2. On the other hand, Cook (2001) states that an L2 user has the feature of holding L1 and L2 in his/her mind in an intermingled way. There is no clear separation between the knowledge, meanings of L2, and L1 in the learners' minds. In the light of these, understanding the role of the L1 can be significant for adult learners who are within L2 learning programs in different environments, specifically where most of the learners are from similar academic qualifications with similar L1 proficiency. It might be worth questioning for those to internalize certain grammatical structures and instructions provided in English concerning comparable skills in their L1. Hall (2018) stated that there was a clear need for balancing L1 and L2 use by describing the acceptable amount and time in the teaching environment.

The studies conducted by Debreli and Oyman (2006), and Kocaman and Aslan (2018) focused on the learners' views on L1 use in the language classroom. Debreli and Oyman (2006) conducted their study with 303 Turkish learners of English at a preparatory school of a private university. The responses to the questionnaire indicated that the students had positive perceptions regarding the inclusion of L1 in their classes and that especially students with lower-level proficiency in English had more positive perceptions. In line with these findings, Kocaman and Aslan's study (2018) found that students at private high schools were willing to use L1 as its use helped them better understand the explanations. For example, the study conducted by Brevik and Rindal (2020) observed lower secondary English lessons with 179 students and their experiences of being exposed to the target language and the use of other languages to support learning this. The analysis of the videos of the observed classrooms as well as the participants' perceived experiences indicates that the official language or the schooling language was the main shared/common language used to support the teaching process and that there were only a few references to the use of other languages in some languages with limited and/or infrequent references to students' other linguistic repertoires. The results also indicated that the participants found the use of schooling language useful in learning the target language.

\section{Methodology}

In line with the aim of the study, the following research questions were proposed: 1) Is there a statistically significant difference between the scores obtained in the post-tests by the control and the experimental groups when the test instructions were provided in L1 and L2? 2) What are the students' views on the instructions provided in L1 and L2 in listening activities? 


\section{Research Design, Context, and Participants}

The present study adopted a quasi-experimental research approach using a posttest-only design since it did not include the use of random assignment. Also, it is a mixed research method that involved two methods of gathering data, both quantitative and qualitative. In this study, the quantitative results were collected first, and then qualitative data were collected to enrich the findings. The study was carried out in the preparatory monolingual classes in the School of Foreign Languages of a state university in Turkey in the spring term of the 2016-2017 academic year. The total duration was 8 weeks with two hours of instruction per week for both groups. The participants of the study were the students who were placed in A2 level classes concerning the examination of the previous module that stood for the placement exam and all shared Turkish as their L1 (Table 1).

Table 1. Control and experimental groups

\begin{tabular}{|c|c|}
\hline Control group (A2 level) & Experimental group (A2 level) \\
\hline 24 participants (9 male, 15 female) & 24 participants (10 male, 14 female) \\
\hline L1: Turkish & L1: Turkish \\
\hline No English prep class before & No English prep class before \\
\hline Instructions in L2 (English) & Instructions in L1 (Turkish) \\
\hline Post-test & Post-test \\
\hline
\end{tabular}

\section{Procedure}

Starting with the first lesson, the researcher as both the implementer of the study and instructor initiated separate Turkish and English principled instruction giving in both groups. The control group was exposed to listening activities and the instructions in English as they were provided in the coursebook. In addition, they were asked instruction check questions all the time in English. On the other hand, the experimental group was exposed to the same listening activities, but the instructions were provided in Turkish. The classes were not observed, and the study was conducted throughout 8 weeks in the same way. In the eighth week, after the final class, the post-test was given to both groups to obtain students' final scores. Both groups were given the same post-test, but in the experimental group, the instructions were provided in Turkish, while those were in English in the control group. The scores obtained from post-tests were analysed statistically. The following day the interviews were held with the participants from the experimental group. 5 female and 4 male students volunteered to be interviewed one by one.

\section{Interviews}

Interviews were conducted as semi-structured interviews in the participants' L1 (Turkish) in the researcher's office. The interview questions were prepared in 
Turkish before conducting the interviews. However, to encourage participants to express themselves, share their experiences, and raise issues that were not covered in the interview questions, they were allowed to ask impromptu questions. The participants were coded using the letters of the alphabet to protect their identities. The interviews with participants were taped and the researcher took notes where necessary. The duration of individual interviews varied from 20 to $35 \mathrm{~min}-$ utes. The participants were expected to answer the following interview questions: 1) Do you think that receiving the instructions in Turkish is helpful for you while doing listening exercises or activities? Why, why not? 2) When the instruction is given in Turkish, how often do you need to re-ask about it to the teacher? If yes, what could be the possible reasons for? 3) Do you prefer to ask the teacher or classmates when you have difficulty in comprehending the instructions provided in Turkish during the lesson? Why? 4) How does it affect the pace of the lesson to receive the instruction in Turkish? Why? 5) How does it affect your level of concentration on the lesson when you receive the instruction in Turkish, positively or negatively? What are the reasons?

\section{Data Analysis}

The quantitative data gathered from the post-test scores were analysed on IBM SPSS 24.0 through independent samples t-test and descriptive statistics. For the qualitative aspect of the study, the audio recordings of the interviews were transcribed and were coded within distinctive words, phrases, and sentences. The responses of the participants were coded into segments that represented the main ideas during the first cycle of the coding process, and during the second cycle, these codes were re-categorised into more generalised codes. Furthermore, the transcripts and the coding reports were shared with two experts in the field to further ensure the validation of the codes.

\section{Results}

The results revealed that when the experimental group participants were provided with L1 instructions before listening activities, their performance in the post-test increased significantly compared to the control group participants who were exposed to L2 instructions. Moreover, L1 instructions were positively received by the participants due to several reasons such as clear instructions on what was expected of participants. However, it was also indicated that L1 use must be carefully planned as it might lead to other issues such as lack of exposure to L2. These results have been discussed in detail in the following section.

To answer the first research question, the participants' scores obtained in the post-tests were statically analysed using IBM SPSS (Version 24.0) software. Table 2 presents independent samples t-test results based on the placement exam scores. As seen in Table 2, there is no statistically significant difference between 
the means of placement scores of the control group and the experimental group $\left(\mathrm{t}_{(46)}=.120, \mathrm{p}=.905, \mathrm{p}>.05\right)$. This means that based on placement scores these two groups are statistically equal to each other. Table 3 presents independent t-test results on post-test Scores.

Table 2. Independent Samples t-test results based on Placement Scores

\begin{tabular}{|c|c|c|c|c|c|c|}
\cline { 3 - 7 } \multicolumn{2}{c|}{} & Mean & St.D. & $\boldsymbol{t}$ & sd & $\boldsymbol{p}$ \\
\hline \multirow{3}{*}{ Placement } & Control & 68.67 & 13.84 & 0.12 & .46 & .905 \\
\cline { 2 - 7 } & Expr. & 68.17 & 14.896 & & & \\
\hline
\end{tabular}

As it can be seen in Table 3, a statistically meaningful difference was obtained between the means of the scores obtained from students' post-tests $\left(\mathrm{t}_{(46)}=-2.112\right.$, $\mathrm{p}=.04, \mathrm{p}<.05)$. This means that the mean of the experimental group's post-test scores $(X=73.54)$ is higher than the mean of the control group's post-test scores $(X=65.21)$. The results indicate that the participants in the experimental group, who were exposed to instructions in L1, performed better in the test compared to the control group participants' post-test scores. In the study, the effect size was obtained as 0.609 for both groups' means and standard deviation values of post-tests.

Table 3. Independent t-test results on Post-test Scores

\begin{tabular}{|c|c|c|c|c|c|c|}
\cline { 3 - 7 } \multicolumn{2}{c|}{} & Mean & St.D. & $\boldsymbol{t}$ & sd & $\boldsymbol{p}$ \\
\hline \multirow{3}{*}{ Post-Test } & Control & 65.21 & 14.998 & -2.112 & 46 & .04 \\
\cline { 2 - 7 } & Expr. & 73.54 & 12.201 & & & \\
\hline
\end{tabular}

\section{Participants' views on L1 and L2 instructions in listening activities}

The second aim of the study was to determine the participants' views as regards the instructions. On the whole, participants $(n=6)$ said that they found the use of L1 helpful. They claimed that it contributed to following the steps of the activity easily. Also, they stated that it gave the feeling of dealing with something familiar to them. One of them mentioned that he felt like it helped him not getting lost in the process of listening to the audio file. They also stated that they were able to make educated guesses about the possible answers to the audio exercises thanks to the instructions in Turkish. Two participants $(n=2)$ said that they felt neutral and found no difference in comparison to getting instructions in English based on their past classroom experiences.

Additionally, participants' preferences regarding whom to ask a question were discussed. Four of the participants $(n=4)$ stated that they wanted to ask the teacher as he was the only authority in the class, and he seemed to volunteer to answer. 
Two of them added that classmates might not listen to the instructions carefully although they were in Turkish and they were afraid of not being able to complete the activities appropriately. Four participants $(n=4)$ preferred to ask their classmates about what was expected to do in the activities as the teacher would not respond in their L1 (Turkish). They thought that their classmates seemed more available and it was a type of solidarity.

The frequency of asking the teacher more about the instruction given in Turkish was also questioned. One participant $(n=1)$ said that she felt free to ask in Turkish to make the instruction clearer. She also revealed that she wanted to benefit from the unique time span to communicate in Turkish. Two participants $(n=2)$ answered the question with the frequency adverb hardly ever and shared that it was easy to deal with a minor failure in comprehending the instruction since it was provided in Turkish. One of them said that she needed to re-ask when she could not fully concentrate on the lesson due to personal issues. The other one needed to ask when the teacher spoke fast while giving the instruction. Six of the participants $(n=6)$ responded that they did not have to re-ask as the instructions were clear and easy to comprehend and they followed the instruction check questions of the teacher.

Moreover, the effect of receiving instructions on the pace of the lesson was commented on by the participants. Seven participants $(n=7)$ answered positively. They believed that it decreased the number of students' questions about what to do before the listening activity started. Moreover, they mentioned that they became more focused on the activities and followed the steps easily. They observed that the teacher could switch to another listening activity fast without the necessity to paraphrase the instruction with simpler vocabulary items in English. One participant $(n=1)$ stated that the same amount of time would be used with the instruction in English. She also stated that more time could be allowed while listening rather than during giving instructions. Finally, the participants were asked about their level of concentration in terms of receiving instruction in Turkish. Six participants $(n=6)$ responded positively. One of them found the use of L1 necessary and added that he could understand what he was going to do during the activity. Most of the participants stated that receiving the instruction in Turkish was for the sake of doing listening activity exercises successfully.

\section{Discussion}

The main findings revealed that the experimental group participants exposed to instructions in L1 obtained higher scores compared to the control group exposed to the instructions in L2. The study also found that instructions provided in L1 were viewed positively due to several factors such as clear instructions of what to do before listening activities. In this study, the post-test scores presented the experimental group's moderately more successful performance. These findings and interpreta- 
tion are in alignment with Oflaz (2009) since his study revealed that understanding the instructions given in the exams was very important as it helped learners to know what to do while answering the questions. The post-test scores revealed the experimental group's moderately more successful performance than the control group. This result might reflect that L1 (Turkish in the study context) might have a role especially in providing instructions. These findings are partially in alignment with the statistical results of the study conducted by Paker and Karaağaç (2015), who found that L1 was an integrated part of teaching a language. Moreover, the use of L1 provided various functions such as enabling the topic/meaning clear by providing examples, presenting extra explanations before certain tasks, and describing complex concepts or ideas in the instructions before exercises or exam procedures.

As for an overall inference, in this study learners might have become sure of the tasks and felt more confident before the activities started. Respectively, they might have revealed better performance in the post-test. In light of this inference, it can be said that the facilitative role of L1 might assist learners in coping with instruction related hindrances. It can be said that these findings are partially parallel with the statistical results of Mayo and Hidelgo's (2017) study, which indicated their findings certified the facilitative role of the L1 that fundamentally served to assist learners as they handled unknown vocabulary items in the instructions. Based on the findings of Mayo and Hidelgo (2017), it was revealed that the participants resorted to L1 more repetitively the second time they dealt with the task. The results indicated the facilitating function of the L1 for the fulfilment of the tasks by the students in a foreign language context.

It might be stated that the findings of this study echoes Bhooth, Azman, and Ismail's (2014) results since the experimental group's more successful performance on a medium scale could be a minor indicator of an increased level of students' engagement in the listening activities. Based on these findings, it was proposed that L1, in the case of the Arabic language, might be used by students as a kind of learning strategy such as translating new words, describing concepts, and assisting each other in their group activities. Moreover, Bhooth et al. (2014) stated L1 would be utilised by the teachers as an instructional method to empower learners' comprehension and raise the level of their participation in the teaching environment. Yet, teachers need to be sure that students do not excessively depend on L1. Although this study revealed a medium effect of L1 use on learners on a limited scale, there still might be indications of the constructive effect of controlled L1 use. Namely, it can be said that a limited and controlled way of using L1 might result in moderately better performances among lower-level L2 learners such as A2 level students in this study. It can be said that Taşkın's (2011) study is not in alignment with this study in terms of complete exposure to L2 by the learners. Within the discussion of her findings, Taşkın (2011) supported that teachers should know what to do in every single stage of the lesson regardless of which skill it was. 
In this study, interviewees claimed that receiving instruction in L1 contributed to following the steps of the activity easily. In addition, they stated that it supported the feeling of dealing with something familiar to them. They implied that they were able to determine what they would do during the tasks and felt more focused before the activities started. These findings show parallelism with Gündüz's (2012) findings, which indicated that the common reason for using L1 was to comprehend complex concepts and to ask for detailed explanations.

About the responses of the students, it might be said that students preferred to comply with the feature of the activity without feeling the need for interaction with the teacher in L1. This finding partly corroborates that of Ghorbani's (2011) study. Ghorbani (2011) pointed out that the use of L1 in the L2 classroom could be interpreted with respect to features of the classroom activity and student/teacher's interaction. Based on the responses to the third interview question, four participants said that they would prefer to ask the teacher if they had difficulty in comprehending the instructions provided in Turkish as he was the only authority in the class and he seemed to volunteer to answer. At this point, as most of the students tended to interact due to their reasons, instruction in L1 might cause interference or confusion. Moreover, it might also weaken students' preferences to interact with each other.

Depending on the findings of the study and the discussion, it might be suggested that A2 level adult learners in EFL classes might perform moderately better in listening activities or exercises such as multiple-choice, true/false statements, and multiple matching and matching exchanges when instructions are provided in L1 by the teacher. It can also be stated that receiving instruction in L1 may lead students to obtain better results in examinations in accordance with their performances during class hours. In addition, students might focus on the content of the listening material and the following tasks without experiencing comprehension problems related to the instructions of the listening task. With respect to common responses in the interview, it can be stated that receiving the instruction in L1 may help students to focus on what they will do during listening, which might help decrease the level of debilitating form of anxiety caused by high-stakes language tests. However, judicious and intentional use of L1 must be considered (Shin, Dixon, \& Choi, 2020), and whenever possible, L2 Language use should be encouraged.

\section{Conclusion}

The current study aimed to investigate the effects of proving instructions in L2 listening activities on the participants' performance in the classroom and the participants' views regarding the use of L1. The study included 48 students in the preparatory classes in the School of Foreign Languages, at a state university in Turkey. Through the post-test only quasi-experimental research design, the participants' performance was compared in classes with L1 and L2 instructions in 
the listening activities. The results indicated that the participants in the experimental group scored higher than those in the control group who were exposed to L2 instructions. The study also revealed that the participants viewed L1 instructions positively. However, one caveat witch was pointed out by them was that this also increased the frequency of resorting to L1 in the classroom interaction. The study also had some limitations. The current study was a small-scale study with a limited number of participants. In addition, the participants were selected using convenience sampling and it was not possible to conduct a true experimental study and only reflected practice in the prep class at a state university. Therefore, the sample size of the study and the number of participants might not allow broad decisions to be made. However, it is also due to note that results could be transferable to other similar contexts where learners have the same L1 and learn English as a foreign language.

\section{Acknowledgement.}

This study is based on the M.A. thesis of the first author, which was submitted to the Institute of Educational Sciences at Burdur Mehmet Akif Ersoy University in 2020 under the supervision of the second author.

\section{References}

Atkinson, D. (1987). The mother tongue in the classroom: A neglected resource? ELT Journal, 41(4), 241-247. DOI: 10.1093/elt/41.4.241.

Bhooth, A., Azman, H., \& Ismail, K. (2014). The role of the L1 as a scaffolding tool in the EFL reading classroom. Procedia - Social and Behavioral Sciences, 118,76-84. DOI: 10.1016/j. sbspro.2014.02.011.

Brevik, L. M., \& Rindal, U. (2020). Language use in the classroom: Balancing target language exposure with the need for other languages. TESOL Quarterly. DOI: 10.1002/tesq.564.

Cook, V. (2001). Using first language in the classroom. The Canadian Modern Language Review, 57(3), 402-423. DOI: $10.3138 / \mathrm{cmlr} .57 .3 .402$.

Debreli, E., \& Oyman, N. (2016). Students' preferences on the use of mother tongue in English as a foreign language classroom: Is it the time to re-examine English-only policies? English Language Teaching, 9(1), 148-162. DOI: 10.5539/elt.v9n1p148.

Gabrielatos, C. (2001). L1 use in ELT: not a skeleton, but a bone of contention. Bridges, 6, 33-35. Retrieved May 12, 2019, from https://www.researchgate.net/publication/261708832.

Ghorbani, A. (2011). First language use in foreign language classroom discourse. Procedia - Social and Behavioral Sciences, 29, 1654-1659. DOI: 10.1016/j.sbspro.2011.11.408.

Greggio, S,. \& Gil, G. (2007). Teachers' and learners' use of code switching in the English as a foreign language classroom: A qualitative study. Linguagem \& Ensino, 10(2), 371-393. Retrieved April 15, 2019, from https://www.academia.edu/17118173/Teachers_and_learners_use_of_ code-switching_in_the_English_as_a_oreign_language_classroom_a_qualitative_study.

Gündüz, Ş. (2012). The use of L1 in ELT classrooms: The preferences of the students and instructors at Middle East Technical University Northern Cyprus campus school of foreign languages. (Unpublished master's thesis). European University of Lefke, Lefke, Turkey.

Hall, G. (2018). Own-language use in ELT. The TESOL Encyclopaedia of English language teaching, 1-7. DOI: 10.1002/9781118784235.eelt0933. 
Jingxia, L. (2008). How much the first language is there in teachers' talk in EFL classroom? The Open Applied Linguistics Journal, 1, 59-67. DOI: 10.2174/1874913500801010059.

Kocaman, O., \& Aslan, E. (2018). The students' perceptions of the use of L1 in EFL classes: A private Anatolian high school sample. Journal of Language and Linguistic Studies, 14(4), 179-189. Retrieved February 11, 2019, from http://www.jlls.org/index.php/jlls/article/download/997/429.

Lee, H. (2018). Role of the first language. The TESOL Encyclopaedia of English language teaching, 1-11. DOI:10.1002/9781118784235.eelt0654.

Levine, G. S. (2011). Code choice in the language classroom. Bristol: Multilingual Matters.

Lewicka-Mroczek, E., \& Wajda, E. (2017). Use of the first language in the EFL classrooms as viewed by English philology students. Linguodidactica, 21, 165-179. DOI: 10.15290/lingdid.2017.21.12.

Lightbown, P. M., \& Spada, N. (2020). Teaching and learning L2 in the classroom: It's about time. Language Teaching, 53, 422-432. DOI: 10.1017/S0261444819000454.

Macaro, E. (2001). Analysing student teachers' codeswitching in foreign language classrooms: Theories and decision making. The Modern Language Journal, 85(4), 531-548. Retrieved December 12, 2018, from https://www.jstor.org/stable/1193074.

Mayo, M. D. P. G., \& Hidalgo, M. D. L. Á. (2017). L1 use among young EFL mainstream and CLIL learners in task-supported interaction. System, 67, 132-145. DOI: 10.1016 j.system.2017.05.004.

Najvarová, V. (2011). Observation in foreign language pedagogy research. In S. Pokrivčáková (Ed.), Research in foreign language education (pp. 29-61). Brno: MSD.

Nation, P. (2003). The role of the first language in foreign language learning. The Asian EFL Journal, 5(2), 81-93. Retrieved May 10, 2019, from http://www.asian-efl-journal.com/june_2003_ PN.php.

Oflaz, Ö. (2009). Teachers and students' views on using mother tongue in ELT classrooms (Unpublished master's thesis). Gaziantep University, Gaziantep, Turkey.

Paker, T., \& Karaağaç, Ö. (2015). The use and functions of mother tongue in EFL classes. Procedia Social and Behavioral Sciences, 199, 111-119. DOI: 10.1016/j.sbspro.2015.07.494.

Shin, Y.-Y., Dixon, L. Q., \& Choi, Y. (2020). An updated review on use of L1 in foreignlanguage classrooms. Journal of Multilingual and Multicultural Development, 41(5), 406-419. DOI: 10.1080/01434632.2019.1684928.

Swan, M. (2007). Follow-up to Claire Kramsch's 'classic book review of Lado, 1957, Linguistics across Cultures: History is not what happened: the case of contrastive analysis. International Journal of Applied Linguistics, 17(3), 414-419. DOI: 10.1111/j.1473-4192.2007.00163.x.

Taşkın, A. (2011). Perceptions on using L1 in language classrooms: A case study in a Turkish private university (Unpublished master's thesis). Middle East Technical University, Ankara, Turkey.

Zulfikar, Z. (2018). Rethinking the use of L1 in L2 classroom. Englisia: Journal of Language, Education, and Humanities, 6(1), 43-51. DOI: 10.22373/ej.v6i1.2514. 